\title{
Bibliometric characteristics of the journal Science: Pre-Koshland, Koshland and post-Koshland period
}

\author{
LIMING LIANG, a,b RONALD ROUSSEAU ${ }^{\mathrm{c}, \mathrm{d}, \mathrm{e}}$ \\ a Institute for Science, Technology and Society, Henan Normal University, Xinxiang, 453002, P.R. China \\ ${ }^{\mathrm{b}}$ School of Humanities and Social Science, Dalian University of Technology, Dalian, 116024, P.R. China \\ ${ }^{\mathrm{c}}$ KHBO (Association K.U.Leuven), Industrial Sciences and Technology, B-8400, Oostende, Belgium \\ ${ }^{d}$ K.U.Leuven, Department of Mathematics, Celestijnenlaan 200B, 3001 Leuven (Heverlee), Belgium \\ e Universiteit Hasselt (UHasselt), Agoralaan, B-3590 Diepenbeek, Belgium
}

\begin{abstract}
During the period 1985-1995 Daniel Koshland was Editor-in-Chief of the journal Science. As such he exerted a huge influence on all aspects related to content and lay-out of the journal. This study compares Science's bibliometric characteristics between three periods: a pre-Koshland (1975-1984) period, the Koshland period (1985-1995) and the post-Koshland period (1996-2006). The distributions of document types, the country/territory and institutional distribution of authors, co-authorship data and disciplinary impact measured by subject categories of citations are studied. These bibliometric characteristics unveil some of the changes the journal went through under the leadership of Daniel Koshland.
\end{abstract}

\section{Introduction}

Daniel Koshland passed away on July 23, 2007, aged 87 [SCIENCE, 2007]. To the average scientist Koshland was best known as the former editor-in-chief of the journal Science. Under his editorship between 1985 and 1995 Science became one of the leading scientific journals in the world. However, Koshland was first and foremost an excellent scientist himself. His research in biochemistry earned him multiple awards, including the Lasker Award and the National Medal of Science [SANDERS, 2007; CHI, 2007]. In the 80 s he provided UC Berkeley a leadership role in the biological sciences by heading a large-scale reorganization of the field, including fundraising for two new buildings and the renovation of a third. "He performed three acts in one lifetime: the visionary biochemist, the tireless institution-builder, and the eloquent public communicator", said Joseph Goldstein, the 1985 Nobel Laureate in Physiology or Medicine [SANDERS, 2007].

At the occasion of his death many obituaries have been written [CHI, 2007; SANDERS, 2007; SCIENCE, 2007; TELEGRAPPH, 2007]. The writers of these articles not only admire Koshland's achievements in scientific research, but they all mention his contributions to the journal Science. The article published in The Scientist, for instance,

Received April 1, 2008; Published online April 16, 2009

Address for correspondence:

LIMING LIANG

E-mail: liangliming1949@sina.com 
has as subheading "Berkeley biochemist raised the bar at Science as editor-in-chief", and describes the fact that during his tenure at Science, the journal's impact factor went up from 10.9 to 21.9 [CHI, 2007].

According to Joseph Goldstein [SANDERS, 2007], before Koshland, Science was known as "a good, but stodgy, journal", a "sleepy journal". Over the course of a decade Koshland turned the journal into a major influence on science policy, not only in the United States but even in the world [SCIENCE, 2007; SANDERS, 2007]. Nowadays, for many biomedical or life science scientists publishing at least one article in Science or Nature is considered almost a must. Koshland overhauled the peer-review process of Science, established a board of reviewing editors, oversaw the internationalization of the journal with the launch of an office in Europe and news bureaus around the world, and increased the number of top-quality papers in the physical sciences [SCIENCE, 2007]. Don Kennedy, Science's 2007 editor-in-chief, says: “As a grateful successor, I find traces of Dan's thoughtful influence everywhere at Science." [SCIENCE, 2007] and the British Telegraph Newspaper online reviews observed that Koshland established Science as a rival to the British journal Nature as the world's leading scientific periodical [TELEGRAPH, 2007].

When reading Koshland's obituaries we became interested to study the influence of Koshland on Science from a scientometric point of view. Moreover, over the last years we have been studying some characteristics of this journal, mainly those revealed by the so-called rhythm sequences [LIANG, 2005; LIANG \& AL., 2006]. A scientometric study of the pre-Koshland, Koshland and post-Koshland period seemed to be a natural addition to our investigations. The methodological approach we take is to consider the three periods 1975-1984, 1985-1995 and 1996-2006, and compare scientometric characteristics, such as the number of subfields citing Science. The three periods will be referred to as the pre-Koshland period (pre-K period for short), the Koshland period (K period for short) and the post-Koshland period (post-K period for short).

Data are extracted from Thomson Scientific's Web of Science (WoS in short). The beginning year of the database we used is 1975 , so the pre-K period we investigate spans 10 years, 1975-1984. The K and post-K periods each cover 11 years. All data used in this study were collected in August 2007 except those necessary for calculating the average number of authors per article, which were obtained in January 2008.

\section{Distributions of document types}

The distribution of document types is an important bibliometric characteristic of an academic journal [GLÄNZEL \& MOED, 2002; SMITH, 1999; NICOLAISEN \& FRANDSEN, 2008]. From the change in this distribution one may grasp one aspect of its editorial policy. Three indicators are used to measure the distribution of document types and compare this characteristic between the three periods. The first indicator is the annual 
average of published documents, describing the size (scale) of the journal. The second indicator points to the annual average of certain types of documents, such as "article" or "review". The third indicator refers to the share of different document types. Table 1 lists the classification results and the calculations of these three indicators.

Taking the data search of the pre-K period as an example, we explain how to obtain the data in Table 1. When we search the WoS for document types the following search requirement is used:

$\mathrm{SO}=($ Science $)$ AND PY $=(1975-1984)$

DocType=All document types; Language=All languages; Database=SCI-EXPANDED; Timespan=1975-2007

In this way, 18,091 results were found. Using the function "Refine your results" by clicking on the button "Document Types", we obtained the counts for each document type over the period 1975-1984.

Table 1. Science: document types (1975-2006) (percentages are rounded to one decimal)

\begin{tabular}{|c|c|c|c|c|c|c|c|c|c|c|c|c|}
\hline \multirow[b]{2}{*}{ Type of document } & \multicolumn{3}{|c|}{$1975-1984$} & \multicolumn{3}{|c|}{ 1985-1995 } & \multicolumn{3}{|c|}{$\begin{array}{c}\text { 1996-2006 } \\
\text { (including "News Item") }\end{array}$} & \multicolumn{3}{|c|}{$\begin{array}{c}\text { 1996-2006 } \\
\text { (not including "News Item") }\end{array}$} \\
\hline & Number & $\%$ & $\begin{array}{l}\text { Annual } \\
\text { average }\end{array}$ & Number & $\%$ & $\begin{array}{l}\text { Annual } \\
\text { average }\end{array}$ & Number & $\%$ & $\begin{array}{l}\text { Annual } \\
\text { average }\end{array}$ & Number & $\%$ & $\begin{array}{l}\text { Annual } \\
\text { average }\end{array}$ \\
\hline Article & 9797 & 54.2 & 979.7 & 9782 & 37.9 & 889.3 & 10033 & 33.7 & 912.1 & 10033 & 43.2 & 912.1 \\
\hline Bibliography & 0 & 0.0 & 0.0 & 1 & 0.0 & 0.1 & 1 & 0.0 & 0.1 & 1 & 0.0 & 0.1 \\
\hline Biographical-Item & 0 & 0.0 & 0.0 & 1 & 0.0 & 0.1 & 71 & 0.2 & 6.5 & 71 & 0.3 & 6.5 \\
\hline Book Review & 408 & 2.3 & 40.8 & 2399 & 9.3 & 218.1 & 1166 & 3.9 & 106.0 & 1166 & 5.0 & 106 \\
\hline Correction, Addition & 0 & 0.0 & 0.0 & 0 & 0.0 & 0.0 & 715 & 2.4 & 65.0 & 715 & 3.1 & 65 \\
\hline Correction & 213 & 1.2 & 21.3 & 670 & 2.6 & 60.9 & 187 & 0.6 & 17.0 & 187 & 0.8 & 17 \\
\hline Database Review & 0 & 0.0 & 0.0 & 1 & 0.0 & 0.1 & 1 & 0.0 & 0.1 & 1 & 0.0 & 0.1 \\
\hline Discussion & 0 & 0.0 & 0.0 & 8 & 0.0 & 0.7 & 0 & 0.0 & 0.0 & 0 & 0.0 & 0 \\
\hline Editorial Material & 5205 & 28.8 & 520.5 & 9640 & 37.3 & 876.4 & 6691 & 22.5 & 608.3 & 6691 & 28.8 & 608.3 \\
\hline Item About Individual & 2 & 0.0 & 0.2 & 23 & 0.1 & 2.1 & 5 & 0.0 & 0.5 & 5 & 0.0 & 0.5 \\
\hline Letter & 2332 & 12.9 & 233.2 & 3123 & 12.1 & 283.9 & 3662 & 12.3 & 332.9 & 3662 & 15.8 & 332.9 \\
\hline Meeting Abstract & 2 & 0.0 & 0.2 & 0 & 0.0 & 0.0 & 0 & 0.0 & 0.0 & 0 & 0.0 & 0 \\
\hline News Item & NA & NA & NA & NA & NA & NA & 6524 & 21.9 & 593.1 & - & - & - \\
\hline Note & 73 & 0.4 & 7.3 & 76 & 0.3 & 6.9 & 0 & 0.0 & 0.0 & NA & $\mathrm{NA}$ & NA \\
\hline Reprint & 0 & 0.0 & 0.0 & 0 & 0.0 & 0.0 & 1 & 0.0 & 0.1 & 1 & 0.0 & 0.1 \\
\hline Review & 59 & 0.3 & 5.9 & 107 & 0.4 & 9.7 & 625 & 2.1 & 56.8 & 625 & 2.7 & 56.8 \\
\hline Software Review & 0 & 0.0 & 0.0 & 12 & 0.0 & 1.1 & 79 & 0.3 & 7.2 & 79 & 0.3 & 7.2 \\
\hline Total & 18091 & 100 & 1809 & 25843 & 100 & 2349 & 29761 & 100 & 2706 & 23237 & 100 & 2112 \\
\hline
\end{tabular}

Comments on Table 1.

Before discussing some interesting details we have to point out that since 1996 (the post-K period) WoS does not anymore use the document type 'Note', while introducing the document type 'News Item'. Hence these changes are independent from a change in Science's editorship.

We deduce from Table 1 the following points:

- The total number of documents has been increasing during the three periods: from 18,091 to 25,843 and then to 29,761 . 
- Generally speaking, from the pre-K period to the post-K period also the annual average of documents increased: from 1,809 to 2,349 , and then to 2,706 .

- The main feature of the $\mathrm{K}$ period is the increase in the share of the document type "Book Review". Its share in the total publication output increased from $2.3 \%$ in the pre- $\mathrm{K}$ period to $9.3 \%$ in the $\mathrm{K}$ period. Simultaneously, the annual average rose from 40.8 to 218.1 reviews a year.

- The K period reduced the share of "Articles" from $54.2 \%$ to $37.9 \%$. In the pre-K period the annual average of articles was 979.7 , while in $\mathrm{K}$ period it became 889.3 . Because of the large number of News items during the post$\mathrm{K}$ period comparisons become difficult. Yet, when the new type of "News Item" is not considered, we may compare the "Article" shares among the three periods. In this way we find that the post-K period increases its "Article" share from K period's $37.9 \%$ to $43.2 \%$; the share of publications classified as "Review" also increased during the post-K period.

- News items take $21.9 \%$ of all publications in the post-K period. This reduced the proportions of other document types. The share of News Items even increased over this latest period proving that nowadays Science has a dual function: it acts as a normal scientific journal specialising in fast publication of hot items, and, at the same time, plays the role of a scientific newspaper.

- The K period published more "Editorial Material" than before, accounting for a high of $37.3 \%$ of all publications. If for the post-K period the new type of "News Item" is not considered, we see that the post-K period has the same proportion of "Editorial Material" as the pre-K period.

- The shares of "Letter"-type publications in the three periods are almost the same.

- The percentage of corrections is at its highest during the $\mathrm{K}$ period.

Dan Koshland made the "Editorial Material" especially lively and interesting to read. Robert Tjian described that Koshland's sense of humour also spilled over into his position as editor-in-chief of Science, as many of the approximately 200 editorials he wrote for the journal were in the form of a dialogue with "Dr. Noitall", a dig at know-itall scientists [SANDERS, 2007].

\section{Country/territory and institutional distribution of authors}

Every journal has its author group, described by country/territory and institutional distribution, gender classification, productive authors, and so on [WORMELL, 1998]. Here we compare the country/territory as well as the institutional distribution of 
Science's authors in the pre-K, K and post-K periods. In order to make the sample sets comparable we choose only the countries/territory of authors of documents in the 'article' category. In Table 1 one can see indeed that the number of articles in the three periods is about the same. Table 2 lists the country/territory extension of articles' authors, based on WoS' 'analyze' facility. We observe that the country/territory extension of the pre- $\mathrm{K}$ and $\mathrm{K}$ periods are very similar to each other while, in general, the number of countries/territories of the post-K period increases year by year and is much higher than that of the former two periods. In 2006 authors come from 70 different countries/territories. Part of this can be explained by an increase in the number of independent countries, e.g. from the former Soviet-Union and from former Yugoslavia, but another part is probably due to the special role that Science and Nature have acquired in the scientific community. For comparison's sake we note that the United Nations has 192 member states, and that there are 252 TDL codes on the Internet.

Table 2. Science: Country/territory extension of articles' authors (1975-2006)

\begin{tabular}{cc|cc|cc}
\hline \multicolumn{2}{c|}{ pre-K period } & \multicolumn{2}{c|}{ K period } & \multicolumn{2}{c}{ post-K period } \\
\hline $\begin{array}{c}\text { Publication } \\
\text { year }\end{array}$ & $\begin{array}{c}\text { Number of } \\
\text { countries/ territories }\end{array}$ & $\begin{array}{c}\text { Publication } \\
\text { year }\end{array}$ & $\begin{array}{c}\text { Number of } \\
\text { countries/territories }\end{array}$ & $\begin{array}{c}\text { Publication } \\
\text { year }\end{array}$ & $\begin{array}{c}\text { Number of } \\
\text { countries/territories }\end{array}$ \\
\hline 1975 & 32 & 1985 & 32 & 1996 & 54 \\
1976 & 38 & 1986 & 36 & 1997 & 44 \\
1977 & 33 & 1987 & 32 & 1998 & 54 \\
1978 & 38 & 1988 & 33 & 1999 & 51 \\
1979 & 36 & 1989 & 34 & 2000 & 53 \\
1980 & 36 & 1990 & 34 & 2001 & 54 \\
1981 & 31 & 1992 & 33 & 2002 & 58 \\
1982 & 37 & 1993 & 36 & 2003 & 59 \\
1983 & 31 & 1994 & 35 & 2004 & 56 \\
1984 & 41 & 1995 & 44 & 2005 & 75 \\
& & Average & 35.2 & 2006 & 70 \\
\hline
\end{tabular}

Table 3 shows the institutional distribution of articles' authors, again based on WoS' "analyse" facility, hence no unification of addresses has been performed. In the pre-K and $\mathrm{K}$ periods every year authors working in more than 500 different institutions publish articles in the journal Science. Since the late K period the number of institutions is increasing year by year. For the post-K period the annual average of the number of institutions reaches 917.6. In the year 2006 the total number of institutions is 1075 or an average of 15.3 per country. Of course, this average hides a large inequality between countries: in 2006 we have more than one hundred institutions from the USA, while many countries are represented by just one institute. 
Table 3. Science: Institutional distribution of articles' authors (1975-2006)

\begin{tabular}{cc|cc|cc}
\hline \multicolumn{2}{c|}{ pre-K period } & \multicolumn{2}{c|}{ K period } & \multicolumn{2}{c}{ post-K period } \\
\hline $\begin{array}{c}\text { Publication } \\
\text { year }\end{array}$ & $\begin{array}{c}\text { Number of } \\
\text { institutions }\end{array}$ & $\begin{array}{c}\text { Publication } \\
\text { year }\end{array}$ & $\begin{array}{c}\text { Number of } \\
\text { institutions }\end{array}$ & $\begin{array}{c}\text { Publication } \\
\text { year }\end{array}$ & $\begin{array}{c}\text { Number of } \\
\text { institutions }\end{array}$ \\
\hline 1975 & 426 & 1985 & 464 & 1996 & 812 \\
1976 & 505 & 1986 & 535 & 1997 & 797 \\
1977 & 492 & 1987 & 490 & 1998 & 830 \\
1978 & 510 & 1988 & 507 & 1999 & 835 \\
1979 & 527 & 1989 & 538 & 2000 & 823 \\
1980 & 552 & 1990 & 496 & 2001 & 882 \\
1981 & 530 & 1991 & 556 & 2002 & 950 \\
1982 & 546 & 1992 & 600 & 2003 & 966 \\
1983 & 532 & 1993 & 629 & 2004 & 980 \\
1984 & 582 & 1994 & 689 & 2005 & 1144 \\
& & 1995 & 726 & 2006 & 1075 \\
\hline Average & 520.2 & Average & 566.4 & Average & 917.6 \\
\hline
\end{tabular}

\section{Co-authorship data}

It is well known that the average number of authors per article has been increasing during the last decades [YITZHAKI \& BEN-TAMAR, 1990; DANG \& ZHANG, 2003; GLÄNZEL \& SCHUBERT, 2004]. The journal Science is no exception to this trend. Figure 1 clearly shows how the average number of authors per article increases throughout the three periods studied. For the period 1975-2000 this increase is linear $\left(\mathrm{R}^{2}=0.978\right)$. However, because of the rising tail in Figure 1 the whole curve can better be described by an exponential function: average number of authors $=2.2 \mathrm{e}^{0.038 \mathrm{t}}$, where time $\mathrm{t}=1$ for the year $1975\left(\mathrm{R}^{2}=0.955\right)$. This increase in the number of authors also gives a partial explanation of the increase in the number of countries/territories: the more co-authors the higher the chances that different universities from different countries are involved. 


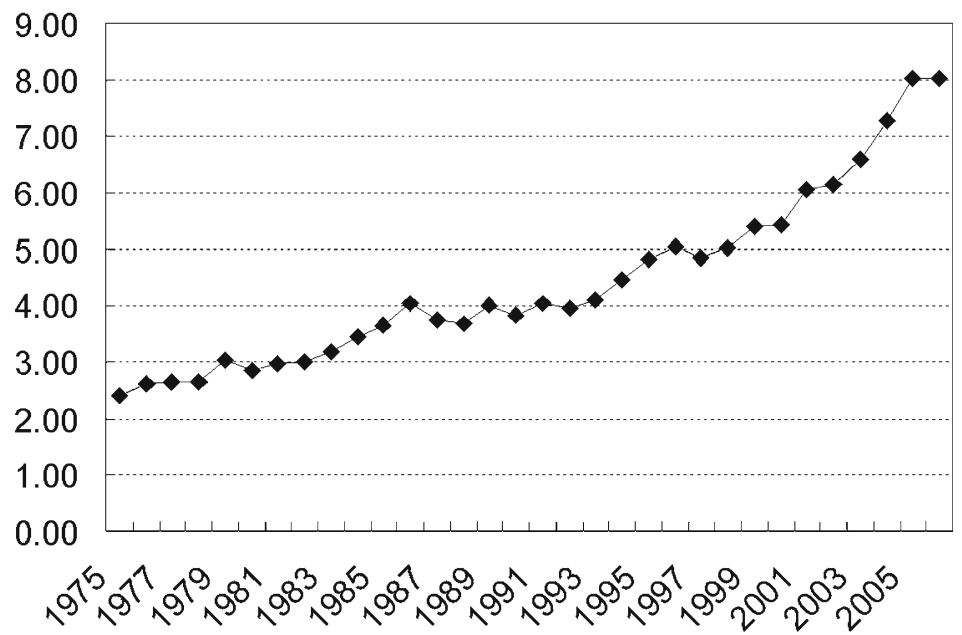

Figure 1. Average number of authors per article

\section{Disciplinary impact measured by subject categories of citations}

In terms of the JCR subject categories the journal Science belongs to the category "multidisciplinary sciences". This means Science's publications cover not one or two subject fields, but various disciplines. Correspondingly, the citations received by Science also come from journals belonging to many categories.

Disciplinary impact is an important bibliometric characteristic of a journal. The impact of a journal on a field is an absolute indicator. It is generally the case that the more articles a journal publishes within a certain discipline the higher its impact on the field. Of course this is even more so for the number of citations a journal receives from a certain field. For a multidisciplinary-sciences journal, like Science, counting its publications in each field would yield a direct description of its impact on that field, while the classification and calculation of citations received leads to another way of gauging its disciplinary impact. Logically, the citation indicator is the more convincible indicator, and most certainly the easiest to determine [GLÄNZEL \& AL., 1999]. Consequently, we decided to investigate Science's disciplinary impact based on Science's citation data, and further to compare Science's disciplinary impact of the $\mathrm{K}$ period to the pre-K and post-K periods. 


\section{How to obtain the subject categories of citations}

ISI's WoS developed a powerful function of analyzing data in many ways, including subject fields. The subject category is our requirement. Taking Science's citation data of its 1975 publications as an example (of a search) we show how to obtain subject categories of citing articles (actually, citing journals). The search was performed on August 11, 2007.

The first step is to use the WoS' "cited ref search" function to search the citations received by the documents published in Science's 1975 issues. The conditions are as follows:

Cited Work=Science AND Cited Year=1975

DocType $=$ All document types; Language $=$ All languages; Databases $=$ SCIEXPANDED, SSCI, A\&HCI; Timespan=1975-2007

In this way we found that Science's documents published in the 1975 issues have been cited by 9,820 documents during the period 1975-2007. Here we would like to give two extra explanations. This number does not imply that all the documents published in 1975 issues are cited - some documents have never received any citation (from the 909 publications in Science, classified by the WoS as 'articles' 74 had not received any citation), and it also does not imply that each of the 9,820 documents just cited one Science's 1975-issue document - there are cases where one citing document cites two or more documents, which were all published in Science's 1975 issues.

The second step is to analyze the subject categories of the 9,820 citing documents. Table 4 is a segment of the results, including "Subject Category", "Record Count" and "\% of $9820 "$ " The last row in the table, i.e. the "total" row, is added by us. Special attention should be paid to the "Records Counts" and the "\% of $9820 "$ ". WoS determines the subject category of a citing document according to the subject(s) affiliation of the journal, where the citing document is published. As many journals are classified in more than one subject category one citing document may belong to two or more subject categories. Thus, usually the total "Record Count" in the subject analysis list may be greater than the number of the original citation records. In our example of the year 1975 , the 9,820 citations belong to 14,142 categories. Accordingly, the sum of the percentages " $\%$ of $9820 "$ in the list reaches $144.01 \%$. In order to deal with this we proportionally reduced the percentages shown in the analysis of subject categories, keeping the percentage sum equal to $100 \%$.

Next we compare the subject impact during the pre-K period, the $\mathrm{K}$ period and the post-K period. Two aspects will be considered: disciplinary broadness of citations received and the disciplines (subject fields) appearing in the top 20. 
Table 4. Results of subject category analysis (segment)

\begin{tabular}{lcc}
\hline \multicolumn{1}{c}{ Field: Subject category } & Record count & $\%$ of 9820 \\
\hline BIOCHEMISTRY \& MOLECULAR BIOLOGY & 1010 & $10.29 \%$ \\
CELL BIOLOGY & 865 & $8.81 \%$ \\
NEUROSCIENCES & 750 & $7.64 \%$ \\
MULTIDISCIPLINARY SCIENCES & 691 & $7.04 \%$ \\
BEHAVIORAL SCIENCES & 407 & $4.14 \%$ \\
ZOOLOGY & 377 & $3.84 \%$ \\
PHARMACOLOGY \& PHARMACY & 360 & $3.67 \%$ \\
PHYSIOLOGY & 339 & $3.45 \%$ \\
\hline Total & 14142 & $144.01 \%$ \\
\hline
\end{tabular}

\section{Disciplinary broadness of citations}

Table 5 lists the number of subject categories of citations in terms of the cited year. For most years the number of subject fields is about two hundred. Observing the average of each period we see that from the pre- $K$ to $K$ and then to the post-K period the average is decreasing slowly. Considering that the papers published in the pre-K period have a longer citation time span, and hence have a higher probability of being cited, it is not difficult to understand that the average number of subject fields from which Science is cited is higher for the pre-K period than for the other two periods. For the same reason, this number is higher for the $\mathrm{K}$ period than for the post-K period. Yet, the numbers are remarkably similar. This analysis leads to the conclusion that as early as thirty years ago Science's subject impact had already reached a remarkable extend. The $\mathrm{K}$ and post-K periods consolidated this impact on many fields.

Table 5. Disciplinary extend of citations by publication year

\begin{tabular}{|c|c|c|c|c|c|}
\hline \multicolumn{2}{|c|}{ pre-K period } & \multicolumn{2}{|r|}{$\mathrm{K}$ period } & \multicolumn{2}{|c|}{ post-K period } \\
\hline $\begin{array}{c}\text { Publication } \\
\text { year }\end{array}$ & $\begin{array}{c}\text { Number of } \\
\text { subject categories } \\
\text { of citations }\end{array}$ & $\begin{array}{c}\text { Publication } \\
\text { year }\end{array}$ & $\begin{array}{c}\text { Number of } \\
\text { subject categories } \\
\text { of citations }\end{array}$ & $\begin{array}{c}\text { Publication } \\
\text { year }\end{array}$ & $\begin{array}{c}\text { Number of } \\
\text { subject categories } \\
\text { of citations }\end{array}$ \\
\hline 1975 & 215 & 1985 & 208 & 1996 & 204 \\
\hline 1976 & 198 & 1986 & 199 & 1997 & 216 \\
\hline 1977 & 208 & 1987 & 200 & 1998 & 207 \\
\hline 1978 & 208 & 1988 & 210 & 1999 & 213 \\
\hline 1979 & 206 & 1989 & 202 & 2000 & 205 \\
\hline 1980 & 219 & 1990 & 214 & 2001 & 192 \\
\hline 1981 & 217 & 1991 & 208 & 2002 & 207 \\
\hline 1982 & 205 & 1992 & 211 & 2003 & 201 \\
\hline 1983 & 210 & 1993 & 202 & 2004 & 192 \\
\hline \multirow[t]{2}{*}{1984} & 204 & 1994 & 206 & 2005 & 179 \\
\hline & & 1995 & 207 & 2006 & 147 \\
\hline Average & 209 & & 206 & & 197 \\
\hline
\end{tabular}




\section{Disciplines appearing among the top 20 subject categories}

Now we investigate which changes took place in the subfields citing Science. Have dominant subject fields changed? How have they changed? In Table 6 we show the counts of the dominant subject fields of each period. Here we selected the top 20 subject fields ranked by the number of citations received. The left hand side of the first row must be read as: the subject "biochemistry \& molecular biology" has ranked in the top 20 for 10 times in pre-K period, for 11 times in $\mathrm{K}$ period and 11 times in post-K period: 32 times in total.

Table 6. Disciplinary appearances in the top 20 ranks, ranked by total number of appearances

\begin{tabular}{|c|c|c|c|c|c|c|c|c|c|}
\hline Discipline & I & II & III & $\mathrm{T}$ & Discipline & I & II & III & $\mathrm{T}$ \\
\hline Biochemistry \& molecular biology & 10 & 11 & 11 & 32 & Materials science, multidisciplinary & 0 & 4 & 5 & 9 \\
\hline Cell biology & 10 & 11 & 11 & 32 & Psychiatry & 7 & 1 & 0 & 8 \\
\hline Multidisciplinary sciences & 10 & 11 & 11 & 32 & Toxicology & 6 & 1 & 0 & 7 \\
\hline Neurosciences & 10 & 11 & 11 & 32 & Medicine, general \& internal & 4 & 2 & 1 & 7 \\
\hline Genetics \& heredity & 7 & 11 & 11 & 29 & Developmental biology & 1 & 2 & 4 & 7 \\
\hline Medicine, research \& experimental & 9 & 11 & 8 & 28 & Physics, atomic, molecular \& chemical & 0 & 2 & 5 & 7 \\
\hline Pharmacology \& pharmacy & 10 & 11 & 7 & 28 & Environmental sciences & 5 & 0 & 1 & 6 \\
\hline Immunology & 5 & 11 & 11 & 27 & Astronomy \& astrophysics & 1 & 1 & 4 & 6 \\
\hline Biophysics & 7 & 11 & 9 & 27 & Infectious diseases & 1 & 1 & 2 & 4 \\
\hline Oncology & 8 & 10 & 8 & 26 & Pathology & 0 & 3 & 0 & 3 \\
\hline Chemistry, multidisciplinary & 3 & 8 & 10 & 21 & Entomology & 2 & 0 & 0 & 2 \\
\hline Biotechnology \& applied microbiology & 0 & 8 & 10 & 18 & Evolutionary biology & 1 & 0 & 1 & 2 \\
\hline Physiology & 10 & 7 & 0 & 17 & Biochemical research methods & 0 & 1 & 1 & 2 \\
\hline Geosciences, multidisciplinary & 6 & 4 & 7 & 17 & Optics & 0 & 1 & 1 & 2 \\
\hline Endocrinology \& metabolism & 8 & 6 & 2 & 16 & Cardiac \& cardiovascular systems & 1 & 0 & 0 & 1 \\
\hline Chemistry, physical & 0 & 7 & 9 & 16 & Chemistry, medicinal & 1 & 0 & 0 & 1 \\
\hline Biology & 8 & 5 & 2 & 15 & Dermatology & 1 & 0 & 0 & 1 \\
\hline Microbiology & 2 & 5 & 8 & 15 & Geriatrics \& gerontology & 1 & 0 & 0 & 1 \\
\hline Plant sciences & 4 & 4 & 7 & 15 & Surgery & 1 & 0 & 0 & 1 \\
\hline Physics, condensed matter & 0 & 6 & 8 & 14 & Geography, physical & 0 & 0 & 1 & 1 \\
\hline Geochemistry \& geophysics & 5 & 2 & 5 & 12 & Physics, fluids \& plasmas & 0 & 0 & 1 & 1 \\
\hline Ecology & 6 & 1 & 5 & 12 & Physics, mathematical & 0 & 0 & 1 & 1 \\
\hline Physics, applied & 0 & 6 & 6 & 12 & Chemistry, analytical & 0 & 1 & 0 & 1 \\
\hline Hematology & 1 & 6 & 4 & 11 & Meteorology \& atmospheric sciences & 0 & 1 & 0 & 1 \\
\hline Physics, multidisciplinary & 1 & 3 & 7 & 11 & Oto-, rhino-, laryngology & 0 & 1 & 0 & 1 \\
\hline Virology & 2 & 5 & 4 & 11 & Gastroenterology \& hepatology & 0 & 1 & 0 & 1 \\
\hline Behavioral sciences & 9 & 0 & 0 & 9 & Physics, particles \& fields & 0 & 1 & 0 & 1 \\
\hline Zoology & 9 & 0 & 0 & 9 & Polymer science & 0 & 1 & 0 & 1 \\
\hline Clinical neurology & 7 & 2 & 0 & 9 & Radiology, nuclear medicine\& Medical imaging & 0 & 1 & 0 & 1 \\
\hline
\end{tabular}

I: pre-Koshland period; II:Koshland-period; III:post-Koshland period; T: Total.

Based on the data (details not shown) obtained in this way we observe the following.

- Considering the three periods together "biochemistry \& molecular biology", "cell biology", "multidisciplinary sciences" and "neurosciences" are the four subject fields citing Science the most. They appear in the top 20 ranking for 10 times in the pre-K period, 11 times in the $\mathrm{K}$ period and 11 times in the post-K period. This means that during the whole period 1975 to 2006 each year the four subject fields rank among the top 20 . 
- In the $\mathrm{K}$ period there are nine subject fields ranking in the top 20 in each of the eleven years. These subject fields all belong to the life sciences and medicine, with the (partial) exception of "multidisciplinary sciences". This means that in the K period Science's publications exert the highest influence in the life sciences and medicine. The year 1990 is a typical year: the top 20 subject fields are all subject fields in the life sciences and medicine, except "multidisciplinary sciences". The year 1985, when Koshland came into the position of Science's editor-in-chief, is another typical year.

- The subject "biotechnology \& applied microbiology" got good achievements since the K period: in the pre-K period it never ranked in the top 20, but since the K period it came into the top 20 for about half of the years.

- Some pre-K period's dominant subject fields, such as "behavioural sciences", "zoology", "clinical neurology" and "psychiatry" have lost their position since the K period, and are replaced by subject fields in chemistry or physics. For example, "chemistry, physical" and "physics, condensed matter" never appeared in the top 20 during the pre-K period. In the $\mathrm{K}$ period, however, the two subject fields appear 7 and 6 times, and in the post-K period 9 and 8 times.

- In the pre-K period "biochemistry \& molecular biology" and "neurosciences" occupy the top 1 position for 10 year, the former for 4 years and the later for 6 years. Since the beginning year of the $K$ period "biochemistry \& molecular biology" has been occupying the position of top 1 for 21 years, till 2005.

- In the K and post-K period "cell biology" and "immunology" came quickly to the forefront. "Cell biology" ranked second for five years in the $\mathrm{K}$ period, and for eight years in the post-K period. In the pre-K period "immunology" comes into top 20 for just five years and ranks not high. In the $\mathrm{K}$ and post-K period it has been in the top 20 and ranks higher.

- The years 1987 and 1995 during the Koshland period are two excellent years for "physics". In 1987 "physics, condensed matter" ranks second and "physics, multidisciplinary" ranks fourth. This high rank for physics fields is not surprising as that year was the year superconductivity at 'high' temperatures was the hot topic. Of course, the journal Science was also involved in the debates and the publication of new results. This involvement culminated in an article published by the 1977 Nobel Prize winner P.W. Anderson [ANDERSON \& AL., 1987] which has been cited more than 4,000 times. In 1995 "physics, atomic, molecular \& chemical" ranks third, "physics, multidisciplinary" ranks fifth and "optics" ranks sixth. Again Nobel Prize winners are involved in a highly-cited Science article. 
This time the 2001 Nobel Prize winners Eric A. Cornell and Carl E. Wiemann co-authored an article about Bose-Einstein condensates which has been cited more than 2800 times [ANDERSON \& AL., 1995]. It is said that Koshland recruited John Brauman, a researcher at Stanford University, to help increase coverage of the physical sciences. 'He really pushed that direction,' Brauman said in an interview by The Scientist." [CHI, 2007].

- Since 1991 the top 20 subject fields became more and more diverse. Physics, chemistry, materials science, astronomy \& astrophysics, environmental sciences, geosciences frequently appear in the top 20. However, life science still plays the most important role in the aspect of "earning" citations and diffusing journal impact.

- It seems that Science has lost impact in the field of physiology: this subject ranked among the top 20 for ten years in the pre-K period while it does not appear in the top 20 anymore in the post-K period.

We note that computer science fields (or information science for that matter) do not rank high in Science. In 2006 the first computer science field only ranks 62nd.

\section{Last article}

Returning to the introduction, where we discussed the influence of Daniel Koshland as mentioned in several obituaries we like to point out that Koshland was a real scientist and gatekeeper. Till the year of his death he served 'his' journal, publishing an interesting essay on the types of scientific discoveries, calling it the cha-cha-cha theory [KOSHLAND, 2007], see also [ROUSSEAU, 2007]). In this expression the term cha-chacha stands for charge, challenge and chance. A discovery belongs to the 'Charge' category if the problem is obvious (for example: cure cancer), but the way to solve it is not clear at all. The discoverer is he or she who sees what everyone else has seen and thinks what no one else has thought before. A typical example, provided by Koshland, is Newton's discovery and explanation of gravity. A discovery falls into the 'Challenge' category if it is the response to an accumulation of facts or concepts that were unexplained. Often these facts were brought to the open by individuals referred to as 'uncoverers'. An example is Einstein's theory of special relativity. Solutions to important challenges may lead to paradigm shifts. Finally, a discovery may fall into the 'Chance' category. Such discoveries are, however, not pure luck but 'favour the prepared mind'. A well-known discovery belonging to this category is Fleming's discovery of penicillin. 


\section{Discussion and conclusion}

Reviewers of this article pointed out that our investigations leads to quite a lot of interesting research problems, such as:

- Make a comparison with other journals over the same period. Such a comparison would be very interesting (especially, but not only, a comparison with the journal Nature) as during the Koshland area science and Science both went through a rapid series of changes. Such a comparison would more clearly show which effect Koshland had on his journal.

- What has been the influence of editorial materials on Science's impact factor?

- Can changing editorial policies be related to changing patterns and tendencies in general science policy at the national and international level? What is cause and what is effect, or is there a mutual influence? How can this be measured?

Our article may be considered as an example showing how a scientist can make a lasting impression. It provides testimony of one strategy - among many others - of how to achieve this. Certainly, as Science's editor-in-chief Koshland exerted a huge influence on all aspects related to the journal's content and lay-out. Moreover, he acted as a bridge between a scientific journal (and its publisher) and the (virtual) world of science.

This study is offered as a tribute to Daniel Koshland: he served Science, we measured Science.

RR thanks Liu Yuxian (Tongji University) for helpful remarks about the contents of this article. The authors also thank the reviewers of this article for a number of suggestions improving the content and readability of our article. This work is sponsored by the National Natural Science Foundation of China (Project 70673019).

\section{References}

Anderson, M. H., Ensher, J. R., Matthews, M. R., Wieman, C. E., Cornell, E. A. (1995), Observation of Bose-Einstein condensation in a dilute vapour. Science, 269 : 198-201.

Anderson, P. W. (1987), The resonating valence bond state in $\mathrm{La}_{2} \mathrm{CuO}_{4}$ and superconductivity. Science, $235: 1196-1198$.

CHI, K. R. (2007), Daniel Koshland Dies - Berkeley Biochemist Raised the Bar at Science as Editor-in-Chief, July 25, 2007, at http://www.the-scientist.com/news/home/53391/\#comments

DANG, Y., ZHANG, WL. (2003), Internationalization of mathematical research. Scientometrics, 58 : $559-570$. 
GlänZEL, W., Moed, H. F. (2002), Journal impact measures in bibliometric research. Scientometrics, $53: 171-193$.

GlänZEl, W., Schubert, A. (2004), Analysing scientific networks through co-authorship. In: H. MoED, W. GLÄNZEL, U. SCHMOCH (Eds), Handbook of Quantitative Science and Technology Research. Kluwer, pp. $257-276$.

GlänZEl, W., SChUbert, A., Czerwon, H.-J. (1999), An item-by-item subject classification of papers published in multidisciplinary and general journals using reference analysis. Scientometrics, $44: 427-439$.

Koshland, D. E. Jr. (2007), The cha-cha-cha theory of scientific discovery. Science, 317 : 761-762.

LiANG, L. M. (2005), The R-sequence: A relative indicator for the rhythm of science. Journal of the American Society for Information Science and Technology, 56 : 1045-1049.

Liang, L. M., Rousseau, R., Shi, F. (2006), A rhythm indicator for science and the rhythm of Science. Scientometrics, $68: 535-544$.

NiCOlaisen, J., FrAnDSEn, T. F. (2008), The reference return ratio. Journal of Informetrics, 2 : $128-135$.

RousSEAU, R. (2007), Cha-cha-cha in informetrics. ISSI Newsletter, 3 (3) : 43-45.

SANDERS, R. (2007), Eminent biochemist Daniel Koshland has died, at http://www.berkeley.edu/ news/media/releases/2007/07/24_koshland.shtml

Science (ANON.) (2007), In memoriam: Dan Koshland, 1920-2007. Science, 317(5837): 441. DOI: $10.1126 /$ science.317.5837.441b

Smith, L. C. (1999), Journal of the American Society for Information Science (JASIS): past, present and future. Journal of the American Society for Information Science, 50 : 965-969.

Telegraph (ANON.), Daniel Koshland. Telegraph Newspaper Online, July 27, 2007, at http://www.telegraph.co.uk/news (search for Koshland)

YitZHAKI, M., BEN-TAMAR, D., Multiple authorship in biochemistry and other fields; a case study of the Journal of Biological Chemistry throughout 1905-1988. In: L. EGGHE, R. RouSSEAU (Eds), Informetrics 89/90. Elsevier, pp. 373-389, 1990.

WORMELL, I. (1998), Informetric analysis of the international impact of scientific journals; how international'are the international journals? Journal of Documentation, 54 : 584-605. 